\title{
OS ESTÁGIOS CURRICULARES SUPERVISIONADOS NOS CURSOS DE LICENCIATURA EM EDUCAÇÃO FÍSICA: UMA REVISÃO SISTE- MÁTICA
}

\author{
Vinicius Kofahl Macedo \\ Universidade do Estado de Santa Catarina, Florianópolis, Santa Catarina, Brasil \\ Gabriela Breggue da Silva Sampaio \\ Universidade Federal de Santa Catarina, Florianópolis, Santa Catarina, Brasil \\ Gelcemar Oliveira Farias \\ Universidade do Estado de Santa Catarina, Florianópolis, Santa Catarina, Brasil \\ Renato Daniel Trusz \\ Prefeitura Municipal de Balneário Camboriú, Balneário Camboriú, Santa Catarina, Brasil \\ Iris Dantas da Mota \\ Universidade do Estado de Santa Catarina, Florianópolis, Santa Catarina, Brasil \\ Marcos Paulo Vaz de Campos Pereira \\ Universidade do Estado de Santa Catarina, Florianópolis, Santa Catarina, Brasil
}

\begin{abstract}
Resumo
O objetivo do estudo foi revisar sistematicamente a produção científica sobre estágios curriculares, nos cursos de licenciatura em Educação Física. O âmbito da pesquisa abrangeu as bases LILACS, SCIELO e EBSCO, a partir das equações: estágio AND Educação Física, estágio curricular supervisionado AND Educação Física, prática de ensino AND Educação Física, estagiários $A N D$ Educação Física e alunos estagiários $A N D$ Educação Física, totalizando 21 artigos para análise. Os resultados evidenciam as dinâmicas dos estagiários no campo de intervenção, a função declarada pelo professor colaborador e seu perfil para atuação. A legislação tem sido um tema em paralelo, de modo a compreender como se situam, na realidade brasileira, os estágios do curso de licenciatura em Educação Física.
\end{abstract}

Palavras-chave: Estágios. Educação Física e treinamento. Formação inicial.

\section{Introdução}

O estágio curricular supervisionado nos cursos de formação de professores, a ser realizado a partir da segunda metade do curso (BRASIL, 2002), contempla a articulação de saberes adquiridos nas fases anteriores da formação inicial. Investigações sobre os estágios na área da Educação Física estão centradas no estagiário e nas ações vinculadas ao contexto de intervenção (FARIAS et al., 2008; BATISTA; PEREIRA; GRAÇA, 2012; RIBEIRO et al., 2015); 
no papel e na atuação do professor supervisor de estágio (BENITES, 2012; BENITES et al., 2012); na legislação que orienta os estágios nos cursos universitários destinados à formação de professores (SILVA; SOUZA; CHECA, 2010).

Em consonância com a legislação brasileira, o estágio curricular supervisionado se faz presente no currículo do curso de licenciatura em Educação Física, com carga horária de 400 horas, e situa-se na segunda metade do curso. Busca-se, neste espaço de intervenção prática, a efetiva constituição de um professor que se mostre reflexivo sobre sua profissão. O estágio caracteriza-se como um importante momento na formação do discente, que lhe possibilita a consolidação de competências em sua prática de ensino, no que concerne a seu futuro papel de professor (BENITES; SOUZA NETO; HUNGER, 2008).

As Diretrizes Curriculares Nacionais orientam, junto às Instituições de Ensino Superior (IES), propostas de formação dos professores de Educação Física, plasmando a identidade docente na perspectiva da constituição de um professor que assuma o processo de reflexão sobre o exercício da profissão docente. Uma das propostas presentes na política de ensino é o estágio curricular supervisionado, um momento da formação do graduando que deve promover a vivência e a consolidação das competências exigidas para o exercício acadêmico profissional (BENITES; SOUZA NETO, 2005; BENITES; SOUZA NETO; HUNGER, 2008).

A resolução CNE 02/2015, que define as Diretrizes Curriculares Nacionais para a formação inicial em nível superior, estabelece orientações acerca da carga horária para a formação continuada; para os estágios nos cursos de graduação, de licenciatura; para cursos de formação pedagógica para graduados não licenciados; para cursos de segunda licenciatura. Em consequência, a adequação dos currículos existentes, visando à efetivação das diretrizes, acarreta desafios às IES (BRASIL, 2015).

Estudos envolvendo os estágios curriculares, na realidade nacional, têm procurado identificar as preocupações específicas da intervenção prática dos estudantes de Educação Física (LOCH et al., 2005; FARIAS et al., 2008; RIBEIRO et al., 2015; COSTA FILHO; LAOCHITE, 2015), ciências (BEJARANO; CARVALHO, 2003a,b; 2004; OLIVEIRA, 2009), enfermagem (BURGATTI; BRACIALLI; OLIVEIRA, 2013; MARRAN; LIMA; BAGNATO, 2014; PARANHOS et al., 2015), fonoaudiologia (QUEIROZ et al., 2012), teatro (ALMEIDA JUNIOR, 2013) e áreas diversas (BISCONSINI; FLORES; OLIVEIRA, 2014). Isto mostra a preocupação de diferentes áreas no que concerne aos estágios curriculares supervisionados.

A universidade, segundo Almeida e Pimenta (2014), tem, entre suas finalidades, a de proporcionar espaços para suprir lacunas existentes na formação, com a intenção de possibilitar a efetiva atuação profissional. Os cursos de licenciatura devem, portanto, estabelecer um currículo comprometido com a formação integral do futuro professor, contribuindo para o pleno exercício de suas funções (BERNARDI, 2008).

Fornecer subsídios teóricos aos meios acadêmico e científico, no intuito de promover reflexões sobre essa etapa de formação, é um grande desafio, visto que, a cada reforma curricular, são efetuadas mudanças que impactam significativamente a formação dos futuros profissionais, devido à geração de novos saberes a ela relacionados. Embora se compreenda a relevância de estudos relacionados à temática da formação de professores, as investigações que abordam tal assunto ainda se mostram incipientes. A fim de identificar a produção do conhecimento sobre o estágio curricular supervisionado, o presente estudo objetiva revisar sistematicamente estudos que abordam os estágios curriculares na formação inicial, nos cursos de licenciatura em Educação Física. 


\section{Método}

Trata-se de um estudo descritivo, com abordagem qualitativa que se traduz em uma revisão sistemática de literatura. A pesquisa qualitativa tem particular relevância no estudo das relações sociais, devido à pluralização de ambientes, subculturas, estilos e formas de vida (GIL, 2010). A revisão sistemática ou grounded theory é uma forma de pesquisa que apresenta metodologia muito exigente, planejada, explícita e sistematizada, a qual serve para buscar, identificar, selecionar e analisar estudos sobre determinado tema, geralmente provindo de uma pergunta bastante pontual (FLICK, 2009).

Esse tipo de pesquisa busca critérios de inclusão e de exclusão, conforme a análise dos conteúdos da literatura selecionada. Após a seleção dos estudos, são realizadas comparações entre objetivos, métodos e resultados apresentados. Ao término, conclui-se sobre o que a literatura informa em relação à pergunta elaborada para a investigação em pauta, indicando também problemas e questões que requerem novos estudos (SAMPAIO; MANCINI, 2007).

Com base nos pressupostos explicitados, este estudo versa sobre as investigações primárias que abordaram o estágio curricular supervisionado no processo de formação inicial de professores de Educação Física. Utilizou-se, como referência, a ficha de pesquisa grounded theory proposta por Saur-Amaral (2011). A ficha de pesquisa é um instrumento que busca identificar as fontes de informação relevantes (de natureza qualitativa ou quantitativa); selecionar estudos ou relatórios a serem considerados, conforme os critérios de inclusão e exclusão; avaliar a qualidade de cada estudo; sintetizar os resultados e apresentar um balanço imparcial sobre eles.

O âmbito da pesquisa abarcou as bases de indexação LILACS, SCIELO e EBSCO, pela abrangência de artigos originais publicados em periódicos das áreas da Educação Física, Educação e Esporte. Para a busca das informações, foram elencadas as seguintes equações de pesquisa: estágio $A N D$ Educação Física; estágio curricular supervisionado $A N D$ Educação Física; prática de ensino $A N D$ Educação Física; estagiários $A N D$ Educação Física; alunos estagiários $A N D$ Educação Física. Foi utilizado o operador booleano $A N D$ para formar os conjuntos de descritores das equações. A busca de informações foi realizada no ambiente da universidade, pois o acesso às bases de dados é permitido somente para as IES.

Os critérios de inclusão adotados na seleção automática, primeiro passo realizado nas bases de indexação, foram: a) artigos originais publicados de 2000 a 2014; b) artigos escritos em língua portuguesa. Para a seleção manual, realizada pelos pesquisadores, e pelo consenso, os critérios foram: a) artigos originais publicados em periódicos; b) estudos relacionados ao currículo do curso de licenciatura em Educação Física; c) estudos relacionados à formação inicial de profissionais de licenciatura em Educação Física. Os critérios de exclusão elencados para esta revisão foram: a) estudos que não disponibilizavam textos completos; b) estudos que não abordavam o estágio curricular supervisionado no curso de licenciatura em Educação Física; c) estudos publicados em língua estrangeira; d) estudos em que os sujeitos investigados vinculavam-se a outros cursos de licenciatura ou bacharelado.

Para alcançar qualidade e validade metodológica, a coleta de dados foi realizada concomitantemente por dois investigadores. No que se refere à seleção automática, quando os investigadores encontraram diferenças em relação ao número de estudos, foi realizada nova busca, respeitando-se, com rigor, os critérios de inclusão e de exclusão. A seleção manual foi realizada mediante a avaliação duplo-cego de títulos, resumos e, posteriormente, dos textos completos. Na seleção manual, quando houve divergências entre os pesquisadores, recorreuse ao consenso, ou seja, a um pesquisador com competência na área, para auxiliar no processo de inclusão ou exclusão de estudos.

Durante a seleção dos estudos, conforme as equações de pesquisa nas bases de dados, foi realizado o print screen para cada equação, em cada base, sendo as informações armaze- 
nadas em um documento do Word for Windows. Após a primeira busca, os critérios foram aplicados utilizando-se os filtros de pesquisa e realizando novamente o print screen para cada equação, em cada base, com os devidos filtros. De acordo com os resultados, efetuou-se a listagem dos textos pré-selecionados em um quadro no Word for Windows com a distinção de autores, ano de publicação, título e resumo do estudo. Foram aplicados, então, os critérios de exclusão, mediados pelos pesquisadores e pelo consenso, restando somente aqueles que foram elencados para a análise. Pela elaboração dos quadros, efetivaram-se a sistematização e a categorização dos dados obtidos na pesquisa.

\section{Resultados}

Pelos resultados identificaram-se, inicialmente, 2.082 estudos, dos quais 465 atenderam aos critérios de seleção sistematizados nas bases de dados (Tabela 1). O processo de busca inicial foi feito pela aplicação das equações com os descritores nas bases de produção científica, sem a utilização de nenhum critério de inclusão ou exclusão. Por este processo, deu-se início à aplicação de filtros disponibilizados nos sites de pesquisa, caracterizando a pesquisa automática.

Tabela 1 - Resultados da busca inicial e da seleção automática, conforme as bases de dados

\begin{tabular}{ccc}
\hline BASE & BUSCA INICIAL & SELEÇÃO AUTOMÁTICA \\
\hline SCIELO & 76 & 62 \\
EBSCO & 147 & 120 \\
LILACS & 1859 & 283 \\
TOTAL & $\mathbf{2 0 8 2}$ & $\mathbf{4 6 5}$ \\
\hline
\end{tabular}

Fonte: Elaborado pelos autores, 2016.

Para a efetivação da busca em cada base, foram inseridos, de forma combinada com o operador booleano $A N D$, os seguintes descritores: estágio AND Educação Física; estágio curricular supervisionado AND Educação Física; prática de ensino AND Educação Física; estagiários AND Educação Física; alunos estagiários AND Educação Física. Considerando as bases de dados e os descritores, foram encontrados 465 estudos. A Tabela 2 apresenta os resultados de cada equação.

Tabela 2 - Resultados da busca inicial e seleção automática conforme as equações

\begin{tabular}{|c|c|c|}
\hline EQUAÇÃO & $\begin{array}{l}\text { BUSCA } \\
\text { INICIAL }\end{array}$ & $\begin{array}{l}\text { SELEÇÃO AU- } \\
\text { TOMÁTICA }\end{array}$ \\
\hline $1^{\text {a }}$ Estágio AND Educação Física & 342 & 145 \\
\hline $\begin{array}{l}2^{\mathrm{a}} \text { Estágio curricular supervisionado AND Edu- } \\
\text { cação Física }\end{array}$ & 11 & 11 \\
\hline $3^{\text {a } \text { Prática de ensino AND Educação Física }}$ & 1699 & 287 \\
\hline $4^{\mathrm{a}}$ Estagiários AND Educação Física & 26 & 19 \\
\hline $5^{\mathrm{a}}$ Alunos estagiários AND Educacão Física & 4 & 3 \\
\hline TOTAL & 2082 & 465 \\
\hline
\end{tabular}

Fonte: Elaborado pelos autores, 2016. 
No intuito de elencar as equações em cada base, a Tabela 3 apresenta a quantidade de estudos encontrados por meio de cada equação. Destaca-se que a base LILACS foi aquela que obteve o maior número de estudos (1.859 estudos), assim como a equação prática de ensino AND Educação Física (1.699 estudos).

Tabela 3 - Resultados da busca inicial e automática conforme as bases de dados, comparando com as equações

\begin{tabular}{|c|c|c|c|c|c|c|}
\hline \multirow{2}{*}{$\begin{array}{l}\text { Base } \\
\text { Equação }\end{array}$} & \multicolumn{2}{|c|}{ EBSCO } & \multicolumn{2}{|c|}{ LILACS } & \multicolumn{2}{|c|}{ SCIELO } \\
\hline & $\begin{array}{l}\text { Busca } \\
\text { inicial }\end{array}$ & $\begin{array}{c}\text { Seleção au- } \\
\text { tomática }\end{array}$ & $\begin{array}{l}\text { Busca } \\
\text { inicial }\end{array}$ & $\begin{array}{c}\text { Seleção au- } \\
\text { tomática }\end{array}$ & $\begin{array}{l}\text { Busca } \\
\text { inicial }\end{array}$ & $\begin{array}{c}\text { Seleção au- } \\
\text { tomática }\end{array}$ \\
\hline $\begin{array}{l}\text { Estágio } A N D \\
\text { Educação Física }\end{array}$ & 104 & 94 & 255 & 41 & 13 & 10 \\
\hline $\begin{array}{l}\text { Estágio curricular } \\
\text { supervisionado } \\
A N D \text { Educação } \\
\text { Física }\end{array}$ & 3 & 3 & 6 & 6 & 2 & 2 \\
\hline $\begin{array}{l}\text { Prática de ensino } \\
A N D \text { Educação } \\
\text { Física }\end{array}$ & 29 & 13 & 1615 & 226 & 55 & 48 \\
\hline $\begin{array}{l}\text { Estagiários AND } \\
\text { Educação Física }\end{array}$ & 10 & 9 & 12 & 9 & 4 & 1 \\
\hline $\begin{array}{l}\text { Alunos Estagiários } \\
\text { AND Educação } \\
\text { Física }\end{array}$ & 1 & 1 & 1 & 1 & 2 & 1 \\
\hline TOTAL & 147 & 120 & 1859 & 283 & 76 & 62 \\
\hline
\end{tabular}

Fonte: Elaborado pelos autores, 2016.

Finalizada a seleção automática, iniciou-se o processo de seleção manual, o qual possibilitou a inclusão ou a exclusão de estudos, por meio da análise dos resumos e dos textos completos dos estudos pré-selecionados e das investigações que atendiam ao objetivo da revisão proposta. Nesta etapa, os pesquisadores utilizaram um terceiro indivíduo, responsável pela realização de consenso dos estudos. Restaram 21 produções científicas (Tabela 4). A base de dados LILACS apresentou 12 produções científicas, tendo mais produções que as bases de dados SCIELO e EBSCO somadas (9). 
Tabela 4 - Quantidade de estudos selecionados após a realização da seleção manual

\begin{tabular}{|c|c|c|c|c|}
\hline \multirow{3}{*}{ BASE } & \multirow{3}{*}{$\begin{array}{r}\text { BUSCA } \\
\text { INICIAL }\end{array}$} & \multicolumn{3}{|c|}{$\begin{array}{l}\text { REFINAMENTO } \\
\end{array}$} \\
\hline & & \multirow{2}{*}{$\begin{array}{l}\text { SELEÇÃO AUTOMÁTI- } \\
\text { CA }\end{array}$} & \multicolumn{2}{|c|}{ SELEÇÃO MANUAL } \\
\hline & & & RESUMO & $\begin{array}{c}\text { TEXTO COMPLE- } \\
\text { TO }\end{array}$ \\
\hline SCIELO & 76 & 62 & 4 & 3 \\
\hline EBSCO & 147 & 120 & 6 & 6 \\
\hline LILACS & 1859 & 283 & 12 & 12 \\
\hline TOTAL & 2082 & 465 & 22 & 21 \\
\hline
\end{tabular}

Fonte: Elaborado pelos autores, 2016.

\section{Discussão}

A análise dos estudos selecionados indica que a maioria deles apresenta dados acerca dos saberes docentes, da prática e da reflexão aplicada do estagiário durante suas intervenções (RAMOS; GRAÇA; NASCIMENTO, 2006; FALKENBACH, 2006; MARTINY; GOMESDA-SILVA, 2011; QUARANTA; PIRES, 2013a,b; COSTA; BATISTA; GRAÇA, 2013; MARTINY; GOMES-DASILVA, 2014a,b; METZNERI, 2014). Alguns estudos apresentam resultados que discutem o curso e a formação do estagiário, bem como expõem reflexões sobre a formação do docente e sobre como a docência é sistematizada durante os estágios curriculares supervisionados (NUNES; FRAGA, 2006; KRÜGER; KRUG, 2006; FERNANDES; ALMEIDA JÚNIOR, 2013).

Um estudo apresenta resultados relacionados à temática das preocupações pedagógicas de estudantes em situação de estágio, sendo a dimensão 'impacto' aquela em que os acadêmicos demonstraram níveis mais altos de preocupação. Contudo, a análise dos resultados evidencia que foi a dimensão 'tarefa' que manteve os níveis de baixa, média e alta preocupação, podendo ser comparada com a prática e a reflexão do estagiário durante suas intervenções (FARIAS et al., 2008).

Ao analisar os resultados, conforme o bloco de objetivos centrados no papel e na atuação do professor colaborador, percebe-se variação nos tipos de estudos realizados, assim como nos instrumentos e nos resultados. As evidências encontradas mostram que a generalidade dos estudos reportou-se aos papéis e às características do professor colaborador (BENITES et al., 2012); às articulações dos estágios com a legislação; às instituições de ensino superior (SILVA; SOUZA; CHECA, 2010); às competências e aos conhecimentos dos estudantes estagiários, sob a perspectiva dos professores colaboradores (RESENDE et al., 2013).

A revisão sistemática de Silveira, Batista e Pereira (2014) revela que a maior parte das investigações, que envolvem o professor colaborador, foi realizada entre os anos de 2008 e 2014, mostrando a ascensão de estudos relacionados à supervisão pedagógica. Essa contribuição dos autores reporta o aumento do número de estudos que tratam, direta ou indiretamente, do papel do professor colaborador e expõem as características e capacidades requeridas durante o processo de supervisão.

Os estudos teóricos foram localizados em todas as categorias analisadas na presente revisão. Alguns estudos explicitam relatos e experiências referentes aos estágios, nos cursos de Educação Física de universidades privadas do Brasil (FILGUEIRAS; RODRIGUES; VERENGUER, 2007; RAMOS, 2007). Um estudo identifica, em resoluções, documentos, leis e artigos, a reflexão dos currículos junto ao estágio curricular supervisionado, discutindo e valo- 
rizando o estágio como uma disciplina fundamental na preparação do profissional docente (CARVALHO FILHO; FERRARI OISHI; TEIXEIRA, 2008). De forma diagnóstica sobre as práticas dos estagiários, uma das investigações analisa a coerência dos planos de aulas com as propostas pedagógicas adotadas pelos discentes. São aí identificados procedimentos de ensino-aprendizagem, por meio da análise dos objetivos e dos procedimentos metodológicos, bem como da avaliação dos planos de aulas e da intervenção dos estagiários. Os resultados revelam haver divergências nos componentes didáticos de procedimentos e de avaliação, contudo a maior representatividade dos resultados demonstra coerência entre as propostas pedagógicas e as práticas exercidas pelos estagiários (MARTINY; BASTOS NETO; GOMES-DA-SILVA, 2012). A fim de melhor entender os estudos, foram abertas as seguintes categorias de análise: objetivo do estudo, método adotado, principais resultados.

\section{Foco dos estudos: seus objetivos}

Após a leitura sistematizada, os objetivos dos estudos analisados foram inseridos em quatro blocos: estudos centrados nas dinâmicas dos estudantes nos campos de estágio (RAMOS; GRAÇA; NASCIMENTO, 2006; NUNES; FRAGA, 2006; KRÜGER; KRUG, 2006; FALKENBACH, 2006; FARIAS et al., 2008; MARTINY; GOMES-DA-SILVA, 2011; QUARANTA; PIRES, 2013a,b; COSTA; BATISTA; GRAÇA, 2013; FERNANDES; ALMEIDA JÚNIOR, 2013; MARTINY; GOMES-DASILVA, 2014a,b; METZNER, 2014); estudos centrados no papel e na atuação do professor colaborador (SILVA; SOUZA; CHECA, 2010; BENITES et. al, 2012; RESENDE et al., 2013; SILVEIRA; BATISTA; PEREIRA, 2014); estudos teóricos que estabeleceram propostas de estudos sobre estágios e o centro de ensino superior (CARVALHO FILHO; FERRARI OISHI; TEIXEIRA, 2008; MARTINY; BASTOS NETO; GOMES-DA-SILVA, 2012); articulação com a legislação (FILGUEIRAS; RODRIGUES; VERENGUER, 2007; RAMOS, 2007).

Os estudos com objetivos relacionados aos professores, que orientavam ou supervisionavam a prática docente dos estagiários, identificam a preparação dos estagiários para a realidade da escola (RESENDE et al., 2013) e o papel do professor colaborador na legislação e na intervenção do estágio (BENITES et al., 2012).

Evidencia-se que a figura do professor colaborador torna-se preponderante na formação do futuro docente, pois é ele quem propõe as orientações para a atuação no estágio e segue o estudante diariamente em suas atividades, de modo a consolidar, de forma eficaz, o ensino e a aprendizagem. Para a efetivação dessas ações, ele deve contemplar sua realização pessoal na profissão, demonstrando sua dedicação e seu envolvimento com ela. $\mathrm{O}$ ato de ser um docente, durante o estágio, significa, portanto, buscar primordialmente atuar no auxílio e na preparação dos futuros professores, os quais cumprem o período de estágio obrigatório e buscam redimensionar as experiências didáticas e pedagógicas adquiridas na IES (CYRINO, 2012).

Os estudos de natureza teórica, ou seja, aqueles que remetem à reflexão sugerem e estabelecem links com propostas; lançam o olhar para as ações futuras; desencadeiam novas articulações; possibilitam unir o conhecimento de hoje e o conhecimento gerado ao longo das décadas. Eles também constituem investigações desenvolvidas pelos pesquisadores preocupados com o estágio.

Os ensaios teóricos e os estudos de revisão sistemática tinham como objetivo identificar a aprendizagem nos estágios com formas de registros (FERNANDES; ALMEIDA JÚNIOR, 2013) e pressupostos estabelecidos na legislação brasileira (CARVALHO FILHO; FERRARI OISHI; TEIXEIRA, 2008); definir os papéis dos atores que mobilizam os estágios (SILVEIRA; BATISTA; PEREIRA, 2014); discutir sobre a demanda de propostas pedagógi- 
cas que articulam os estágios, mobilizando a prática e os saberes (MARTINY; GOMES-DASILVA, 2011; MARTINY; BASTOS NETO; GOMES-DA-SILVA, 2012).

Os conhecimentos e os saberes do docente devem se basear em alguns fatores que compõem a formação do profissional, como questões disciplinares, curriculares e experienciais. É exigida a articulação de diferentes conteúdos para formar os saberes e os conhecimentos do professor, buscando o equilíbrio entre competência técnica, compromisso políticopedagógico, regimento da instituição. Os saberes docentes são compreendidos como um objeto de múltiplos aspectos, construído em âmbito sociocultural, com a perspectiva de poder ser modificado ao longo do tempo (BENITES; SOUZA NETO, 2005; BENITES; SOUZA NETO, 2006).

O bloco que obteve maior número de publicações científicas é formado pelas dinâmicas do discente, abordando, entre outros temas: objetivos; processos didáticos dos estágios para a efetivação da aprendizagem dos alunos (METZNER, 2014); história de vida dos estagiários (QUARANTA; PIRES, 2013); relação entre a teoria adquirida nas disciplinas universitárias e a prática do professor na escola (NUNES; FRAGA, 2006); saberes docentes dos estagiários (MARTINY; GOMES-DA-SILVA, 2011); desafios da intervenção pedagógica e a reflexão sobre a prática (FALKENBACH, 2006; MARTINY; GOMES-DA-SILVA, 2014a).

Os objetivos dos estudos estabelecem uma relação intrínseca entre formação inicial, estagiário e atuação, na perspectiva de interagir com seu futuro desempenho como professor, após a conclusão de sua formação inicial. A essência do estágio curricular supervisionado é a de formar e sustentar a prática pedagógica do futuro professor, através de subsídios fornecidos pelas IES, pelas instituições escolares, por professores e colegas de aula ou obtidos pelos próprios alunos. Esse conjunto de saberes adquiridos, oriundos de diversas fontes, necessita ser trabalhado de forma prática e com uma atuação reflexiva focada no saber fazer, visando melhorar, através da prática pedagógica, a condição de ser professor (BENITES, 2012).

\section{Caracterizando os estudos: o método em questão}

Ao analisar o método de cada estudo, considerando a população e a amostra, verificase que as maiores demandas das investigações foram realizadas com discentes em situação de estágio, ora de forma individual, ora em conjunto com os seus professores orientadores ou supervisores. Os professores orientadores, que em alguns estudos foram nomeados professores colaboradores, também foram abordados tanto em conjunto com seu discente como individualmente (SILVA; SOUZA; CHECA, 2010; BENITES et al., 2012; COSTA; BATISTA; GRAÇA, 2013; RESENDE et al., 2013).

Outros estudos documentais utilizam, como fonte de informação, relatórios finais de estágio, planos de ensino, relatos de experiências de estagiários (MARTINY; GOMES-DASILVA, 2011; MARTINY; BASTOS NETO; GOMES-DA-SILVA, 2012), assim como registros pedagógicos, livros, documentos e artigos de periódicos existentes nas bases de dados online (FILGUEIRAS; RODRIGUES; VERENGUER, 2007; SILVEIRA; BATISTA; PEREIRA, 2014). Ainda outras investigações combinaram a coleta de dados com estudantes estagiários e a consulta em fontes documentais (QUARANTA; PIRES, 2013; MARTINY; GOMESDA-SILVA, 2014a,b), possibilitando a análise reflexiva sobre os sujeitos da pesquisa e a literatura disponível. A utilização dessas combinações propicia uma reflexão mais aprofundada a respeito do tema pesquisado, visto que, nesses tipos de pesquisa, existe a possibilidade de adotar a análise de conteúdo em conjunto com os dados coletados através dos sujeitos da pesquisa.

A entrevista é um instrumento de pesquisa em que há o encontro de pessoas com a finalidade de, por meio do diálogo, obter informações a respeito de determinado tema (SANTOS, 2011). Gil (2010) esclarece que a entrevista é conduzida por um entrevistador junto à 
pessoa entrevistada, podendo receber o auxílio de recursos de gravação de áudio ou visual. Esse tipo de instrumento caracteriza uma forma de interação social. Por ser uma ferramenta de coleta utilizada com seres humanos, há vantagens e desvantagens em sua aplicação, sendo necessário selecionar o melhor meio de fazer a entrevista, e de conduzi-la, conforme as características dos sujeitos e os tipos de amostra pretendidos (GIL, 2008; MARCONI; LAKATOS, 2011).

Dentre os instrumentos de coleta de dados adotados pelos pesquisadores, sobressai a entrevista (KRÜGER; KRUG, 2006; RAMOS; GRAÇA; NASCIMENTO, 2006; SILVA; SOUZA; CHECA, 2010; COSTA; BATISTA; GRAÇA, 2013; RESENDE et al., 2013), seguida da observação (MARTINY; GOMES-DA-SILVA, 2014a,b) e do questionário (FARIAS et al., 2008). Alguns estudos combinam instrumentos, de modo a contemplar uma gama maior de resultados, possibilitando mais ampla compreensão do objeto de investigação (FALKENBACH, 2006; NUNES; FRAGA, 2006; BENITES et al., 2012).

\title{
Considerações finais
}

Ao final do estudo, que buscou na literatura as investigações que tematizam os estágios curriculares, nos cursos de licenciatura em Educação Física, identifica-se que o estágio curricular supervisionado tornou-se, recentemente, um tema de pesquisa. Grande parte dos estudos evidencia as dinâmicas dos estudantes estagiários no campo de intervenção, a função de supervisão declarada pelo professor colaborador e o perfil do professor colaborador requerido para atuação. A legislação tem sido um tema paralelo, abordado tanto em estudos teóricos quanto em estudos aplicados, com o intuito de compreender como se situam e definem os estágios do curso de licenciatura em Educação Física, na realidade brasileira.

No que tange aos métodos adotados nos estudos, a abordagem qualitativa sobressai no cenário investigado. A entrevista e a observação são as técnicas de coleta de dados mais utilizadas, produzindo resultados e conhecimento científico sobre o aluno estagiário, o professor colaborador e as articulações do estágio curricular supervisionado. As investigações envolvendo professores colaboradores, supervisores e estudantes estagiários predominam na maioria dos estudos pesquisados.

Os resultados encontrados sinalizam uma grande demanda por dados reflexivos, abrangentes e que contextualizem os estágios. Dados oriundos de estudos desta natureza devem ser propositivos, no sentido de redimensionar a formação inicial dos estágios, definir com clareza o papel de professor orientador e do professor supervisor e valorizar os estudos teóricos, principalmente aqueles que se destinam a relatar a experiência de estudantes em situação de estágio.

Novas investigações relacionadas à temática devem ser realizadas, pois, no momento em que se vislumbram reformas curriculares e novas orientações para os cursos de licenciatura, estudos devem dar suporte às discussões, lançando o olhar da comunidade científica sobre o contexto da legislação e da prática docente.

\section{THE SUPERVISED INTERNSHIPS IN PHYSICAL EDUCATION GRADUATE COURSES: A SYSTEMATIC REVIEW}

\begin{abstract}
The objective of this study was to review systematically the scientific production on internships in graduate courses in Physical Education. The scope of the research covered the databases LILACS, SCIELO and EBSCO, from equations: internship AND Physical Education,


curricular internships supervised AND physical education, teaching practice AND Physical Education, trainees AND Physical Education and students $A N D$ Physical Education, totaling 21 articles for analysis. The results show the dynamics of the interns in the field of intervention, the function declared by collaborating professor and your profile to work. The legislation has been a theme in parallel, in order to understand how are the stages of the course degree in Physical Education, in the Brazilian reality.

Keywords: Internships. Physical Education and Training. Initial formation.

\section{LAS PASANTÍAS SUPERVISADAS EN CURSOS DE GRADO EN EDUCACIÓN FÍ- SICA: REVISIÓN SISTEMÁTICA}

\section{Resumen}

El objetivo del estudio fue examinar sistemáticamente la producción científica sobre pasantías en los cursos de grado en Educación Física. El ámbito de aplicación englobó las bases LILACS, SCIELO y EBSCO, a partir de ecuaciones: pasantía AND Educación Física, pasantía supervisada $A N D$ Educación Física, práctica de la enseñanza $A N D$ Educación Física y estudiantes pasantes $A N D$ Educación Física, totalizando 21 artículos para el análisis. Los resultados muestran la dinámica de los practicantes en el campo de intervención, la función declarada por el profesor colaborador y su perfil

profesional. La legislación ha sido un problema en paralelo con el fin de entender cómo se encuentra en la realidad brasileña, las etapas del curso de Grado en Educación Física.

Palabras claves: Pasantías. Educación Física y Entrenamiento. Grado Académico.

\section{Referências}

ALMEIDA JUNIOR, J. S. Reflexões acerca do estágio curricular na formação do professor licenciado em teatro. Educação em Revista, Curitiba, v. 29, n. 2, p. 43-64, 2013.

ALMEIDA, M. I.; PIMENTA, S. G. Pedagogia universitária - valorizando o ensino e a docência na universidade. Revista Portuguesa de Educação, Minho, v. 27, n. 2, p. 7-31, 2014.

BRASIL. Ministério da Educação. Conselho Nacional de Educação. Resolução CNE/CP No 1, de 18 de fevereiro de 2002. Brasília, 2002. Disponível em: <http://portal.mec.gov.br/seesp/arquivos/pdf/res1_2.pdf>. Acesso em: 31 out. 2015.

BRASIL. Ministério da Educação. Resolução $\mathbf{N}^{\mathbf{0}}$ 2, de $\mathbf{1}^{\mathbf{0}}$ de julho de 2015. Brasília, 2015b. Disponível em: <http://pronacampo.mec.gov.br/images/pdf/res_cne_cp_02_03072015.pdf>. Acesso em: 31 out. 2015.

BATISTA, P. M. F.; PEREIRA, A. L.; GRAÇA, A. B. S. A (re)configuração da identidade profissional no espaço formativo do estágio profissional. In: NASCIMENTO, J. V.; FARIAS, G. O. (Org.) Construção da identidade profissional em Educação Física: da formação à intervenção. Florianópolis: UDESC, 2012. p. 81-111.

BEJARANO, N. R.; CARVALHO, A. M. Tornando-se professor de ciências: crenças e conflitos. Ciência e Educação, Bauru, v. 9, n. 1, p. 1-15, 2003 a.

.Professor de Ciências novato: suas crenças e conflitos. Investigações em Ensino de Ciências, Porto Alegre, v.8 n. 3, p. 257-280, dez. 2003b. 
A História de Ely: um professor de Física no início da carreira. Revista Brasileira de Ensino de Física, São Paulo, v. 26, n. 2, p. 165-178, 2004.

BENITES, L. C.; SOUZA NETO, S.; BORGES, C.; CYRINO, M. Qual o papel do professorcolaborador no contexto do estágio curricular supervisionado na Educação Física? Revista Brasileira de Ciência e Movimento, Brasília, v. 20, n. 4, p. 13-25, 2012.

BENITES, L. C. O professor-colaborador no estágio curricular supervisionado em educação física: perfil, papel e potencialidades. 2012. 180 f. Tese (Doutorado em Educação Física) - Instituto de Biociências, Universidade Estadual Paulista, UNESP, Rio Claro, 2012.

BENITES, L. C.; SOUZA NETO, S. Os saberes docentes e a prática pedagógica nas tendências de ensino da Educação Física. Revista Digital, Buenos Aires, v. 11, n. 103, dez. 2006. Disponível em: <http://www.efdeportes.com/efd103/docentes.htm>. Acesso em: 20 out. 2015.

.Educação Física e formação profissional. Revista Digital, Buenos Aires, v. 10, n. 81, fevereiro. 2005. Disponível em: < http://www.efdeportes.com/efd81/efprof.htm>. Acesso em: 19 out. 2015.

.; HUNGER, D. O processo de constituição histórica das diretrizes curriculares na formação de professores de Educação Física. Educação e Pesquisa, São Paulo, v. 34, n. 2, p. 343-360, maio/ago., 2008.

BERNARDI, G. B. A contribuição da formação inicial de licenciatura em Educação Física da EsEF/UFRGS para a prática docente escolar. 2008. 68 f. Monografia (Graduação em Educação Física) - Universidade Federal do Rio Grande do Sul, UFRGS, Porto Alegre, 2008 .

BISCONSINI, C. R.; FLORES, P. P.; OLIVEIRA, A. A. B. Formação inicial para a docência: estágio curricular supervisionado na visão de seus coordenadores. Journal Physics Education, Maringá, v. 27, jul. 2014.

BURGATTI, J. C.; BRACIALLI, L. M. A. D.; OLIVEIRA, M.A. C. Problemas éticos vivenciados no estágio curricular supervisionado em enfermagem de currículo integrado. Revista da Escola de Enfermagem, São Paulo, v. 47, n. 4, ago. 2013.

CARVALHO FILHO, C.; FERRARI OISHI, L.; TEIXEIRA, M. Estágio supervisionado: desenvolvimento da capacidade profissional do educador físico. Colloquium Humanarum, Presidente Prudente, v. 5, n. 1, p. 74-83, jun. 2008.

COSTA FILHO, R. A.; LAOCHITE, R. T. Experiência de ensino no estágio supervisionado e autoeficácia para ensinar educação física na escola. Revista da Educação Física, Maringá, v. 26, n. 2, abr./jun., 2015.

COSTA, M.; BATISTA, P.; GRAÇA, A. Práticas de ensino em contexto de estágio: reflexões e experiências do estudante estagiário e do orientador da Faculdade. Revista Portuguesa de Ciências do Desporto, Porto, v. 13, n. 3, p. 30-77, 2013. 
CYRINO, M. Formação inicial de professores: o compromisso do professor-colaborador e da instituição escolar no processo de estágio supervisionado. 2012. 233 p. Dissertação (Mestrado em Educação) - Instituto de Biociências, Universidade Estadual Paulista, UNESP, Rio Claro, 2012.

FALKENBACH, A. P. Educação Física na educação infantil: o futuro professor na relação com as crianças. Revista Brasileira de Ciência e Movimento, Brasília, v. 14, n. 1, p. 21-28, 2006 .

FARIAS, G. O.; FOLLE, A.; BOTH, J.; SAAD, M. A.; TEIXEIRA, A. S.; SALLES, W. N.; NASCIMENTO, J. V. Preocupações pedagógicas de estudantes-estagiários na formação inicial em Educação Física. Motriz, Rio Claro, v.14 n.3, p.310-319, jul./set. 2008.

FERNANDES, A. P.; ALMEIDA JÚNIOR, A. S. Aprendizagens no estágio supervisionado: produzindo novas formas e sentidos para os registros. Revista Mackenzie de Educação Física e Esporte, São Paulo, v. 12, n. 1, p. 53-64, 2013.

FILGUEIRAS, I. P.; RODRIGUES, L. H.; VERENGUER, R. C. G. O estágio curricular supervisionado no curso de Licenciatura em Educação Física da Universidade Presbiteriana Mackenzie. Revista Mackenzie de Educação Física e Esporte, São Paulo, v. 6, n. 2, p. 139146, 2007.

FLICK, U. Introdução à pesquisa qualitativa. 3. ed. Porto Alegre: Artmed: Bookman, 2009.

GIL, A. C. Como elaborar projetos de pesquisa. 5. ed. São Paulo: Atlas, 2010.

Métodos e técnicas de pesquisa social. 6. ed. São Paulo: Atlas, 2008.

IZA, D. F. V.; BENITES, L. C.; SANCHES NETO, L.; CYRINO, M.; ANANIAS, E. V.; ARNOSTI, R. P.; SOUZA NETO S. Identidade docente: as várias faces da constituição do ser professor. Revista Eletrônica de Educação, São Carlos, v. 8, n. 2, p. 273-292, 2014.

KRÜGER, L. G.; KRUG, H. N. Desvelando a atuação profissional em Educação Física através da percepção da trajetória acadêmica. Revista Mackenzie de Educação Física e Esporte, São Paulo, v. 5, n. 1, p. 77-92, 2006.

LOCH, M. R.; BRUNO, G. B. M.; OLIVEIRA, E. S. A.; NASCIMENTO, J. V. Preocupações pedagógicas e profissionais de formandos em Educação Física do Sul do Brasil. Revista Digital, Buenos Aires, v. 10, n. 80, jan. 2005. Disponível em: <http://www.efdeportes.com/efd80/brasil.htm>. Acesso em: 4 ago. 2014.

MARCONI, M. A.; LAKATOS, E. M. Metodologia cientifica. 6. ed. São Paulo: Atlas, 2011.

MARRAN, A.L.; LIMA, P.G.; BAGNATO, M. H. S. As políticas educacionais e o estágio curricular supervisionado no curso de graduação em enfermagem. Revista Trabalho, Educação e Saúde, Rio de Janeiro, v.13, n.1, jan./abr. 2015. Epub, dez, 2014.

MARTINY, L. E.; GOMES-DA-SILVA, P. N. “O que eu transformaria? Muita coisa!”: os saberes e os não saberes docentes presentes no estágio supervisionado em Educação Física. Revista da Educação Física/UEM, Maringá, v. 22, n. 4, p. 569-581, out./dez. 2011. 
A transposição didática na Educação Física escolar: a reflexão na prática pedagógica dos professores em formação inicial no estágio supervisionado. Revista de Educação Física / UEM, Maringá, v. 25, n. 1, p. 81-94, jan./mar. 2014a.

A transposição didática na Educação Física escolar: o caminho formativo dos professores em formação inicial. Revista Brasileira Estudos Pedagógicos, Brasília, v. 95, n. 239, p. 175-196, jan./abr. 2014b.

MARTINY, L. E.; BASTOS NETO, J. P.; GOMES-DA-SILVA, P. N. Diários de aula no estágio supervisionado: análise das propostas pedagógicas da Educação Física. Revista Mackenzie de Educação Física e Esporte, São Paulo, v. 11, n. 1, p. 31-43, 2012.

METZNERI, A. C. Proposta didática para o curso de licenciatura em. Educação e Pesquisa, São Paulo, v. 40, n. 3, p. 637-650, jul./set. 2014.

NUNES, R. V.; FRAGA, A. B. "Alinhamento astral": o estágio docente na formação do licenciado em Educação Física na ESEF/UFRGS. Revista Pensar a Prática, Goiânia, v. 9, n. 2, p. 297-311, jul./dez., 2006.

OLIVEIRA, L. C. V. As contribuições do estágio supervisionado na formação do docentegestor para a educação básica. Revista Ensino, Pesquisa, Educação e Ciência, Belo Horizonte, v. 11, n. 2, jul./dez., 2009.

PARANHOS, W. Y.; CHAVES, A. A. B.; FRIAS, M. A. E.; LEITE, M. M. J. Análise do desempenho dos estudantes de enfermagem no ensino por competências e no ensino para compreensão. Revista Escola de Enfermagem, São Paulo, v. 49, n. 2, dez., 2015.

QUARANTA, A. M.; PIRES, G. L. Formação de professores de Educação Física na EAD: inserção na cultura escolar através do estágio supervisionado. Revista Brasileira de Ciência e Movimento, Brasília, v. 21, n. 1, p. 51-65, $2013 \mathrm{a}$.

QUARANTA, A. M.; PIRES, G. De L. Histórias de vida e experiências docentes no estágio supervisionado de licenciandos em Educação Física - Modalidade EAD. Movimento (ESEF/UFRGS), Porto Alegre, v. 19, n. 02, p. 185-205, abr./jun., 2013 b.

QUEIROZ, M. A. S.; TEIXEIRA, C. L. V.; BRAGA, C. M.; ALMEIDA, K. A.; PESSOA, R. X.; ARAÚJO, R. C.; MESQUITA, T. M.; MUNIZ, M. C. M. C. Estágio curricular supervisionado: percepções do aluno-terapeuta em fonoaudiologia no âmbito hospitalar. Revista Cefac, São Paulo, v. 15, n. 1, jan./fev., 2013, Epub, out., 2012.

RAMOS, G. N. S. O ensino na graduação em Educação Física: a experiência dos estágios na UFSCar. Revista Mackenzie de Educação Física e Esporte, São Paulo, v. 6, n. 2, p. 27-35, 2007.

RAMOS, V.; GRAÇA, A. B. S.; NASCIMENTO, J. V. A representação do ensino do basquetebol em contexto escolar: estudos de casos na formação inicial em Educação Física. Revista Brasileira de Educação Física e Esporte, São Paulo, v. 20, n. 1, p. 37-49, jan./mar 2006. 
RIBEIRO, V. T.; FOLLE, A.; FARIAS, G. O.; NAZARIO, P. F. Preocupações pedagógicas e competência profissional de estudantes de Educação Física em situação de estágio. Revista da Educação Física/UEM, Maringá, v. 26, n. 1, p. 59-68, jan./mar., 2015.

RESENDE, R.; LIMA, R. J. F.; ALBUQUERQUE, A. A. C.; BENITES, L. C. A percepção dos professores cooperantes sobre os conhecimentos e as competências dos estudantes. Revista da Educação Física / UEM, Maringá, v. 24, n. 4, p. 519-533, out./dez., 2013.

SAMPAIO, R. F.; MANCINI, M. C. Estudos de revisão sistemática: um guia para síntese criteriosa da evidência científica. Revista Brasileira de Fisioterapia, São Carlos, v. 11, n. 1, p. 83-89, jan./fev., 2007.

SANTOS, S. G. Métodos e técnicas de pesquisa quantitativa aplicada à Educação Física. Florianópolis: Ed. Tribo da Ilha, 2011.

SAUR-AMARAL, I. Revisão sistemática da literatura com apoio de Endnote X4 e NVIVO 9. Aveiro: GOVCOPP, 2011.

SILVA, S. A. P. S.; SOUZA, C. A. F.; CHECA, F. M. Situação do estágio supervisionado em IES privadas da grande São Paulo. Motriz, Rio Claro, v.16 n.3 p.682-688, jul./set., 2010.

SILVEIRA, G. C. P. P.; BATISTA, P. M. F.; PEREIRA, A. L. T. N.O perfil do professor cooperante no contexto da supervisão de estágio profissional: um estudo de revisão sistemática da literatura. Revista da Educação Física/UEM, Maringá, v. 25, n. 2, p. 309-321, abr./jun., 2014.

Recebido em: 01/12/2016

Revisado em: 05/04/2017

Aprovado em: 17/05/2017

Endereço para correspondência:

fariasgel@ hotmail.com

Gelcemar Oliveira Farias

Universidade do Estado de Santa Catarina

Av. Madre Benvenuta, 2007

Itacorubi, Florianópolis / SC

CEP: 88.035-901 